\title{
O processo de civilização e o controle das emoções - alterações sociais e percepção da infância
}

\author{
lone da Silva Cunha Nogueira \\ Universidade Federal de Mato Grosso do Sul (Brasil) \\ Carlos da Fonseca Brandão \\ Universidade Estadual Paulista "Júlio de Mesquita Filho" (Brasil)
}

\section{Resumo}

A preocupação com cuidados e proteção de crianças na sociedade ocidental foi um processo que se desenrolou ao longo de um período histórico. Conforme a teoria dos "processos de civilização" de Norbert Elias, no período medieval, essa sociedade passa a exercer um maior controle sobre o indivíduo, fazendo-the exigências em relação aos comportamentos, em contrapartida modificada numa relação recíproca de mudança. Este artigo tem como objetivo analisar a forma como a sociedade passou a se preocupar com a infância, reconhecendo as crianças como merecedoras de atenção e cuidados, com base na concepção de Norbert Elias de "processos de civilização", bem como a partir de seus conceitos de "figuração", "interdependência", "psicogênese", "sociogênese", "poder" e "habitus". Este estudo possibilitou a compreensão de que um maior controle das emoções trouxe também comedimento dos homens em relação aos indivíduos que poderiam ser considerados mais fracos, categoria na qual, sob determinados aspectos, muitas vezes se incluem as crianças.

Palavras-chave: Infância. Processos de civilização. Controle das emoções. Sociedade.

\section{The civilization process and control of emotions - social change and childhood perception}

\section{Abstract}

The concern with the care and protection of children in Western society was a process that took place over a historical period. According to Norbert Elias' theory of "civilization processes", in the medieval period, this society began to exercise greater control over the individual, making him demands in relation to behaviors, in turn modified in a reciprocal relationship of change. This article aims to analyze the way in which society became concerned with childhood, recognizing children as deserving of attention and care, based on Norbert Elias' conception of "processes of civilization", as well as from his "figuration", "interdependence", "psychogenesis", "sociogenesis", "power" and "habitus" concepts. This study made it possible to understand that greater control of emotions also brought restraint from men in relation to individuals who could be considered weaker, a category in which, in certain aspects, children are often included.

Keywords: Childhood. Civilization processes. Emotion control. Society. 
Processo de civilização e o controle das emoções - alterações sociais e percepção da infância

\section{El proceso de civilización y control de las emociones - cambios socia- les y percepción de la infancia}

\section{Resumen}

La preocupación por el cuidado y la protección de los niños en la sociedad occidental fue un proceso que tuvo lugar durante un período histórico. Según la teoría de los "procesos de civilización" de Norbert Elias, en el período medieval esa sociedad comenzó a ejercer un mayor control sobre el individuo, haciéndole exigencias en relación a los comportamientos, a su vez, modificada en una relación recíproca de cambio. Este artículo tiene como objetivo analizar la forma en que la sociedad llegó a preocuparse de la infancia, reconociendo a los niños como merecedores de atención y cuidado, con base en la concepción de Norbert Elias de los "procesos de civilización", así como a partir de sus conceptos de "figuración", "interdependencia", "psicogénesis", "sociogénesis", "poder" y "habitus". Este estudio permitió comprender que un mayor control de las emociones también trajo moderación de los hombres en relación con las personas que podrían considerarse más débiles, una categoría en la que, en ciertos aspectos, muchas veces se incluyen a los niños.

Palabras clave: Infancia. Procesos de civilización. Control de las emociones. Sociedad.

\section{Introdução}

Apesar da sociedade brasileira do século XXI possuir uma legislação bastante atenta aos cuidados com as crianças e adolescentes, é possível perceber que esses indivíduos, em especial a criança, ainda sofrem com diversas formas de violência. É importante destacar que esse não é um problema recente, mas por muito tempo foi tratado de maneira velada, proporcionando uma falsa sensação de proteção aos pequenos. Nos últimos tempos, porém, várias situações têm sido amplamente expostas por meio da mídia e por relatórios oficiais de governos, bem como de organizações não governamentais.

O processo que deu visibilidade às questões da criança e seus problemas é consequência de uma alteração nas estruturas da sociedade ocidental, na qual ela passa a ser vista como um indivíduo que necessita de atenção, cuidados e proteção. Esse processo se iniciou na Modernidade, quando surgiu uma nova concepção de infância e a criança se tornou alvo do cuidado e atenção dos adultos.

Este artigo tem como objetivo analisar a forma como a sociedade passou a se preocupar com a infância, reconhecendo as crianças como merecedoras de atenção e cuidados com base na concepção de Norbert Elias 
de "processos de civilização", bem como em seus conceitos de "figuração", "interdependência", "psicogênese", "sociogênese", "poder" e "habitus". Elias trabalha com a ideia de civilização das emoções, teoria que propõe alterações para todos os tipos de relações sociais, inclusive as que se dão entre adultos e crianças.

\section{Norbert Elias, a Idade Média e os padrões de vergonha}

Em um trabalho anterior (NOGUEIRA, 2010), indicamos que Norbert Elias fez um estudo histórico e sociológico a respeito do processo de civilização do homem, tomando como ponto de partida o continente europeu na ldade Média. $O$ pensador aponta que esse processo ocorre de duas formas: primeiro por meio do controle individual das emoções e pulsões e, em seguida, mediante o controle e o monopólio da violência e da tributação por parte do Estado. Neste artigo, apenas a primeira questão será investigada.

Elias ( 1993) aponta o porquê da escolha da ldade Média e demonstra que o faz como ponto de partida e não imagina esse período como princípio do processo de civilização, nem como representante de um estágio de "primitividade", mas, sim, por apresentar um padrão diferente do nosso. Não o utiliza por ser melhor ou pior, apenas pela diferença que apresenta em relação ao tempo atual.

Segundo Elias (1993), o comportamento e as emoções dos homens mudam de acordo com as diferentes formas de vida que começam a surgir, às quais o indivíduo precisa se adaptar. De acordo com o sociólogo, conforme surgem formas de vida e funções diferentes, os sentimentos, as emoções e a estrutura de anseios e impulsos também se modificam. Assim, temos que, na sociedade medieval, as pessoas deixavam transparecer seus sentimentos e liberavam seus impulsos de maneira acentuadamente mais rápida e espontânea do que em tempos posteriores, mais especificamente a partir da ldade Moderna, quando as emoções passaram a ser mais controladas.

Enquanto tais emoções eram menos reguladas, também oscilava a violência entre os extremos com maior frequência. Por isso, ao mesmo tempo em que o indivíduo poderia parecer tranquilo em meio à sua vida cotidiana, também poderia tratar com agressividade alguém que the representasse qualquer tipo de ameaça. Elias mostra que a tendência de as pessoas viverem 
em sociedade, observando umas às outras, começou a delinear uma nova característica presente no processo de civilização, a coação de uma pessoa sobre a outra, com o propósito de alterar ou moldar determinados padrões de comportamento.

Para chegar ao estágio de conhecimento e alterações nos padrões de comportamento, compreendido como civilizado, os homens tiveram que passar por diversas mudanças em seu cotidiano e nas relações interpessoais. O cenário social sofreu alterações e os papéis a serem desempenhados pelos indivíduos se modificaram, o que exigiu uma adaptação a essas novas formas de vida e aos novos relacionamentos que surgiram em decorrência das mudanças da sociedade. Despontaram aí outras funções sociais e, como consequência, uma diferente estrutura social passou a se solidificar. Essa é a ideia de interdependência apresentada pelo autor.

Nesse emaranhado de papéis sociais e sentimentos a eles atrelados, percebe-se que os indivíduos estão totalmente ligados entre si com a tarefa de manter a sociedade como um todo. É daí que surgem os conceitos de figuração e interdependência, presentes nas ideias de Elias e apontados por Brandão (2007) como "basilares" em sua teoria dos processos de civilização.

Elias refere-se à figuração dizendo que as relações e as funções sociais devem ser vistas como um conjunto de relações interdependentes, que ligam os indivíduos entre si. A figuração é descrita pelo autor como "[...] a teia de relações de indivíduos interdependentes que se encontram ligados entre si a vários níveis e de diversas maneiras" (ELIAS; DUNNING apud BRANDÃO, 2007, p. 911. Essas figurações estão em fluxo constante, e é exatamente por isso que seu conjunto é compreendido como processo.

No que diz respeito à infância, é importante reconhecer que havia na Idade Média a ausência de envolvimento com as crianças, da forma como são vistas atualmente na sociedade ocidental. $\bigcirc$ historiador Philippe Ariès (1981) defende a inexistência do sentimento de infância durante a ldade Média, definindo esse sentimento como a ausência de consciência a respeito da particularidade infantil, falta de conhecimento sobre as individualidades que distinguem as crianças dos adultos, resultando, assim, em uma incompreensão de que havia uma dependência não somente física, mas também emocional por parte das crianças. $\bigcirc$ autor defende que até o fim do período medieval esse sentimento não estava presente na sociedade. Analisando obras de arte e 
documentos da época, Ariès desenvolve seu estudo e explana que, apenas a partir do século XVII, quando se começa a ter algum controle sobre o alto índice de mortalidade infantil, a criança passa a ser retratada com maior interesse, o que pode demonstrar outro nível de envolvimento com essa fase da vida.

Conforme Elias (1994), o pensamento voltado à infância era bem restrito e a diferenciação entre as formas de tratamento para adultos e crianças era muito pequena. Porém, ressalta que os adultos de então não alcançavam o mesmo patamar dos adultos do século XX, se comparados às estruturas de sentimentos e comportamento social. $\bigcirc$ autor alerta para a questão de que, ao se estudar o sentimento de infância na ldade Média, é preciso ter a preocupação em compreender os padrões existentes na época. É impossível entender vida adulta e infância com base nos critérios e padrões dos séculos XX ou XXI. Embora Elias não tivesse como tema principal a infância e seu desenvolvimento ao longo do processo civilizatório, o sociólogo apresenta algumas informações sobre o sentimento de infância a partir da análise de documentos.

O autor aponta que a primeira impressão de que não havia lugar para a infância na ldade Média deve ser atenuada com a compreensão de que o sentimento dos indivíduos e a percepção da própria sociedade sobre si mesma e suas crianças eram completamente diferentes dos dias atuais. Aos poucos, esse sentimento se tornou mais forte nos indivíduos que puderam, então, perceber a primeira infância como um período importante e único da vida que deve ser cercado de cuidados e proteção.

\section{Norbert Elias e os processos de civilização}

É importante verificar que a configuração do papel dos indivíduos na sociedade não é um processo intencional, nem tão pouco planejado. No desenrolar das vivências em sociedade, os relacionamentos ocorrem e provocam novas reações, que, por sua, vez provocam consequências para a vida em sociedade. Porém, nada disso é planejado ou provocado intencionalmente - nem mesmo os indivíduos diretamente envolvidos com a situação a princípio percebem o seu significado. Tudo acontece conforme as diversas situações são vivenciadas, proporcionando novos aprendizados, passando a exigir atitudes diferentes dos integrantes da sociedade diante do novo. 
Elias investigou essas intrincadas relações sociais e as maneiras como vão se desenvolvendo, atribuindo a esses processos os nomes de "psicogênese" e "sociogênese". Em seus estudos, Norbert Elias lembra que a maneira como os indivíduos agem irá interferir diretamente na sociedade, provocando mudanças, alterando ou desenvolvendo novos modelos das relações de interdependência no decorrer do seu avanço. Tais ocorrências são extremamente importantes nas alterações da personalidade e do comportamento dos indivíduos.

De acordo com Brandão (2007), existe uma relação entre o controle das emoções e esses dois principais eixos conceituais da teoria dos processos de civilização. $O$ autor indica, além disso, que as ideias de psicogênese, de sociogênese e de controle das emoções que formam a teoria dos processos de civilização de Elias não podem ser pensadas ou entendidas separadamente, mas como um conjunto. Segundo Brandão (2007), qualquer tipo de separação realizada deve ter apenas finalidades didáticas, com o objetivo de levar a uma melhor compreensão das ideias de Elias. A psicogênese refere-se às transformações do comportamento humano e das estruturas da personalidade dos indivíduos. A sociogênese é uma teoria do desenvolvimento social que analisa as alterações ocorridas nas diferentes estruturas sociais.

De acordo com Elias, é preciso investigar a transformação da estrutura da personalidade e de toda a organização social para explicar e compreender os processos civilizadores. O sociólogo alemão ressalta que o estudo psicogenético apreende todo o campo das energias psicológicas individuais, "a estrutura e a forma tanto das funções mais elementares quanto as mais orientadoras da conduta do indivíduo". Simultaneamente, é necessário um estudo sociogenético que busca compreender "[...] a estrutura total de um campo social formado por um grupo específico de sociedades interdependentes e da ordem sequencial de sua evolução" (ELIAS, 1993, p. 239).

Ainda de acordo com Elias (1993), com a gradual mudança das funções e instituições sociais, também ocorreu uma transformação da auto-orientação individua. Inicialmente, aconteceu entre os principais grupos da nobreza e da burguesia, depois se estendeu a todos os demais integrantes da sociedade fazendo com que houvesse um aumento nas possibilidades de previsão e uma maior regulação dos impulsos individuais. Elias assevera que, de acordo com o grau de pacificação da sociedade, os indivíduos modificaram seu comportamento, forçando-os a viver pacificamente. $\bigcirc$ fato de viver em uma 
sociedade na qual observar e ser observado, no que diz respeito ao comportamento, fez com que o código de conduta dessa sociedade fosse alterado.

Nesse contexto, o patamar de repugnância também se modificou e alterou a estrutura psicológica fazendo com que o indivíduo se tornasse mais sensivel, o que resultou em alterações no padrão de comportamento. Elias assegura que vergonha e repugnância estão relacionadas ao medo que o indivíduo possivelmente sinta de outro membro da sociedade. Esses sentimentos passam a ser características do processo civilizatório a partir do século XVI.

Percebe-se que a cadeia de inter-relações é forte e tudo se encontra diretamente relacionado na sociedade. As atitudes e os comportamentos individuais não podem ser vistos de maneira isolada dos demais movimentos sociais. Segundo Elias (1993), a atitude de um indivíduo hoje resulta em consequências para toda a sociedade, promovendo alterações nos comportamentos e o modo como os indivíduos do grupo veem a vida. Ainda nessa análise, Brandão (2007) observa que é um erro separar as transformações gerais sofridas pelas sociedades das alterações ocorridas nas estruturas de personalidade dos indivíduos que as compõem na teoria dos processos de civilização proposta por Elias. As primeiras estão diretamente relacionadas às outras e não podem ser vistas como se nada tivessem em comum ou que não se influenciassem mutuamente.

É aqui que surge mais um importante conceito apresentado por Elias: a concepção de poder. Para esse pensador, poder não é algo que pertença a um indivíduo ou apenas a um grupo de indivíduos dentro da sociedade, mas sim uma influência que todos em certa medida têm uns sobre os outros, conformando o que, para ele, trata-se de uma característica estrutural das relações humanas. Desse modo, o equilíbrio de poder constitui um elemento integral de todas as relações humanas, considerando que todos têm poder uns sobre os outros desde que, enquanto indivíduos ou grupo, thes seja atribuído algum valor. $\bigcirc$ autor utiliza como exemplo a criança e seus pais, pois não somente estes exercem poder sobre o filho, uma vez que, de acordo com o valor que a criança representa para os pais, ela também passa a exercer sobre eles algum tipo de poder (ELIAS, 2008).

Da mesma maneira, é importante compreender o conceito de "função", que, conforme Elias, deve ser compreendido não como "tarefa desempenhada por uma parte de uma totalidade harmoniosa "[...] mas, tal como o poder, 
deve ser compreendido como um conceito de relação" (ELIAS, 2008, p. 84). Desse modo, as funções sociais estão relacionadas às interdependências que constrangem as pessoas, o que pode acontecer com maior ou menor grau.

Para o autor, as pessoas ou grupos que desempenham funções recíprocas exercem uma coerção mútua. Quando a retenção de potencial é desigual, um dos lados passa a exercer maior poder coercivo que o outro. Assim, aquele que tem maior potencial de reter o que o outro necessita tem a capacidade de torná-lo mais dependente e, dessa maneira, exercer maior poder sobre ele. Quem tem uma proporção de poder mais elevada pode orientar mais as atividades do outro grupo e exercer maior pressão sobre ele. E, nesse sentido, o poder deve ser temido, porém, enquanto característica estrutural da sociedade, "poder" não pode ser considerado nem bom, nem mau.

Chartier, em prefácio ao livro A sociedade de corte, indica que a esses conceitos pode-se acrescentar a ideia de equilíbrio das tensões, ressaltando que os indivíduos estão estreitamente ligados uns aos outros, o que permite modificar a ideia existente a respeito de liberdade e determinismo. Para Chartier, Elias recusa o terreno da metafísica e "[...] prefere pensar a liberdade de cada indivíduo como inscrita na cadeia de interdependências 8 que o liga aos outros homens e que limita o que the é possivel decidir ou fazer" (CHARTIER, 2001 , p. 13). Assim, é a modalidade variável de cada uma das cadeias de interdependência que define a especificidade de cada formação ou configuração social.

Para Chartier, essa definição dá origem a alguns conceitos que devem ser analisados e considerados na compreensão das relações interpessoais. Em primeiro lugar, é preciso ultrapassar a ideia de oposição entre o homem considerado indivíduo livre e o sujeito singular "homem" considerado ser em sociedade, integrado nas solidariedades e comunidades múltiplas. Depois, é preciso modificar a maneira de considerar as relações intersubjetivas, pensando-as em suas modalidades historicamente variáveis e diretamente dependentes das exigências próprias de cada configuração social. E, por último, essas ideias levam-nos a abandonar completamente a distinção que designa como concretos e reais apenas os indivíduos e trata como abstrações as formas sociais que os ligam uns aos outros. $O$ autor observa, portanto, que, para Elias, uma das questões centrais da sociologia é saber de que modo e por que os indivíduos estão ligados entre si constituindo figurações humanas específicas. 
Com a minimização de tensões e conflitos entre os homens, suas relações poderão tornar-se mais brandas e menos nocivas à sua própria vida e à sociedade. Nesse caso, poderá deixar de ser exceção e tornar-se regra que o individuo alcance o equilíbrio entre as paixões que the exigem satisfação e realização e as limitações impostas. Para o autor, somente quando isso acontecer o homem poderá se dizer civilizado. Até lá, o que temos é o homem em processo de civilização.

\section{O processo de civilização e as alterações nos comportamentos e no controle das emoções}

Voltando à ldade Média, Elias (1994) apresenta um cenário no qual os padrões de comportamento eram muito diferentes dos nossos. Atitudes e maneiras de portar-se em sociedade, segundo o autor, indicavam um maior desprendimento das opiniões alheias e mesmo de noções de higiene e limpeza. Diversos costumes que hoje nos parecem comuns e corriqueiros tiveram sua evolução como processo de civilização de maneira diferenciada e intrigante.

As técnicas de comer na ldade Média, por exemplo, demonstravam um padrão muito especial das relações humanas e das estruturas de sentimentos. De acordo com o autor, como não podemos estudar as maneiras à mesa de forma isolada, pois "[...] elas são um segmento da totalidade de formas socialmente instaladas de conduta [...]" (ELIAS, 1994, p. 80), devemos ficar atentos a esses modos e tomá-los como indícios que nos levem a compreender a sociedade e seu funcionamento. Como exemplo, Elias (1994) aponta que pessoas de classe mais alta tinham preferência de lavar as mãos ao servirem-se de um prato. Tais fatos não podem ser considerados como alterações isoladas, ou como fatos em si, mas pertencentes a um processo mais amplo de modificação da sociedade e dos indivíduos.

A partir do século XVI surgem as exigências e as proibições da sociedade para modelar os indivíduos, como os tratados de boas maneiras, entre os quais Elias destaca o de Erasmo de Rotterdam: A civilidade pueril. De acordo com o autor, esse tratado trouxe à tona uma palavra que, apesar de muito antiga e comum, precisou desse novo impulso incisivo para fazer parte das relações sociais. Trata-se da palavra civilitas. Segundo Norbert Elias: 
Intencionalmente ou não, ele expressou na palavra algo que atendia a uma necessidade social da época. $\bigcirc$ conceito civilitas, daí em diante, ficou gravado na consciência do povo com o sentido especial que recebeu no tratado de Erasmo (ELIAS, 1994, p. 68).

Editado em várias outras línguas, palavras correspondentes foram empregadas, fato que expressa mudanças na vida do próprio povo, principalmente porque os novos conceitos estavam destinados a tornarem-se fundamentais e de longa duração na sociedade. A importância desse tratado situa-se não como obra isolada, mas como um sintoma de mudança, uma concretização de processos sociais daquilo que Elias (1997) chama de habitus. De acordo com Chartier, habitus significa uma economia psíquica ou estrutura da personalidade, mas Elias acredita que possui um sentido de saber social incorporado, sem ser considerado algo fixo e estático. O sociólogo alemão afirma que o habitus muda com o tempo, e isso implica equilíbrio entre continuidade e mudança. O referido tratado pode ser uma evidência de tal alteração, pois levantou um assunto que estava pronto para ser explorado pela sociedade de então, auxiliando a modificar seu comportamento. Isso demonstra que, embora a sociedade medieval ainda não conseguisse alterar completamente seus padrões de comportamento, já estava preparada para iniciar o processo de transformação a qualquer momento.

Erasmo não foi o primeiro a se interessar por esses assuntos. Questões semelhantes ocuparam os homens na ldade Média, na Antiguidade greco-romana e em civilizações anteriores que se assemelhavam a elas. Elias explica a escolha por esse autor da seguinte maneira:

[...] o tratado de Erasmo surge em uma época de reagrupamento social. É a expressão de um frutífero período de transição após o afrouxamento da hierarquia social medieval e antes da estabilização moderna. Pertence a uma fase em que a velha nobreza e cavaleiros feudais estava ainda em declínio, enquanto se encontrava em formação a nova aristocracia das cortes absolutistas (ELIAS, 1994, p. 85).

De acordo com Elias, ao observarmos obras como a de Erasmo, o que realmente importa é que apresentam um avanço no patamar do embaraço e da vergonha sob a forma de "refinamento" ou como prova de "civilização", que antes não existia. É importante observar que um comportamento uniforme 
se tornava uma exigência cada vez maior naquele momento. As pessoas eram forçadas a viver de maneira diferente em sociedade e, para isso, tornavam-se mais sensíveis às pressões do outro. Isso, porém, não ocorreu de maneira súbita, foi lentamente que o código de comportamento se tornou mais rigoroso e aumentou o esperado grau de consideração dos demais. Esse refinamento está relacionado às mais diversas questões, desde maneiras de se portar à mesa até formas de pensar ou de falar.

A obra de Erasmo trata do comportamento das pessoas em sociedade e revela um estilo de vida que se perdeu, de atitudes que atualmente causam vergonha ou asco, mas que estiveram presentes na vida das pessoas como algo corriqueiro em determinado momento. Elias nos revela, porém, que esse comportamento externo é uma representação da manifestação do homem interior e o próprio embaraço que hoje sentimos ao ouvir ou falar sobre as atitudes que Erasmo nos apresenta faz parte do processo de civilização.

Assim, Elias (1994) nos leva a perceber que a civilização é parte de um processo em construção no qual também estamos envolvidos, ao invés de ser algo pronto e acabado, como muitas vezes imaginamos, e fizesse parte integrante do ser humano. Todos os demais componentes, como maquinarias, descobertas científicas, formas de Estado, entre outros, são características que comprovam a existência de uma estrutura social peculiar, que possui formas de comportamento que the são correspondentes.

Outros códigos de boas ou de más maneiras estudados por Elias (1994), provenientes de diversos outros povos - como ingleses, franceses, italianos, alemães, latinos -, apesar de pertencerem a diversas localidades, confirmam o mesmo padrão de relações entre as pessoas, a estrutura da sociedade e a psique medieval. A unidade de comportamento descrita é que deve ser considerada, pois indica a unidade do comportamento concreto na classe superior medieval, que deve constatar que as eventuais diferenças entre esses tratados são insignificantes para o todo.

Havia um importante significado para as normas de comportamento, o de pertencimento a uma determinada classe social. As normas e as maneiras de comportar-se revelavam a classe social do indivíduo e era a classe mais alta que ditava as normas de conduta padrão. Os que pertenciam à classe mais baixa nem sempre poderiam igualar-se à conduta das classes mais altas. Algumas atitudes seriam peculiares à nobreza e outras seriam próprias 
dos camponeses; o comportamento de um e de outro era alvo constante de comparação.

No entanto, mesmo as normas mais elementares de comportamento se dirigiam a adultos. Os procedimentos à mesa eram um aspecto do comportamento social, o que indica que os próprios adultos determinavam comportamentos em cada situação social. Aquele era um momento de aprendizagem, não somente de boas maneiras, mas de modos de comportamento aceitáveis e necessários para um bom desenvolvimento social.

É importante perceber que Elias mostra que os fenômenos triviais, como o comportamento à mesa ou os hábitos de comer carne, de utilizar utensílios ou de portar-se em relação às outras pessoas revelam a estrutura e o desenvolvimento da psique. Para ele, a tendência psicológica acompanha o processo social e, assim, surgiu uma grande repugnância por determinadas situações vivenciadas na sociedade do século XX com o controle das emoções e dos comportamentos sociais da ldade Média. Uma característica de todo o processo chamado de civilização é a tendência cada vez mais incisiva de remover da visão o que é desagradável. Assim, alguns atos eram proibidos não pelo que pudessem racionalmente acarretar, mas apenas como refina12 mento das atitudes e dos comportamentos.

Medo, repugnância, culpa, associações e emoções exageram o perigo real. Pode-se mencionar como exemplo a fraca proibição na ldade Média em relação ao uso de utensílios de mesa como a faca. Naquele momento isso era aceitável, pois a classe dominante de guerreiros estava em constante disposição para lutar e o controle das emoções era reduzido. No entanto, à medida que ocorrem mudanças nos relacionamentos, a preocupação com tudo que possa fazer lembrar momentos de perigo tem seu uso controlado e eliminado da visão. A memória e associação que temos da faca com o perigo, em conjunto com a pacificação da sociedade, limitaram a sua utilização.

Segundo Elias (1994), sentimentos de vergonha e asco, bem como avanços no patamar da delicadeza, são manifestações da natureza humana em condições sociais específicas e reagem sobre o processo sócio-histórico como um de seus elementos. A mesma vergonha que fez com que o uso do garfo e do lenço passassem a existir também transformou a utilização da 
camisola para dormir em algo normal, em lugar do ato de despir-se totalmente ao dormir ou ir às casas de banho.

Percebe-se, de acordo com Elias (1994), que as sociedades se tornam mais pacificadas, porém, o controle social torna-se mais imperativo e lentamente vai modificando a natureza e o mecanismo de controle das emoções. Aliado a essa mudança estrutural da sociedade e acompanhado do novo modelo das relações humanas, surge o impulso de policiar o próprio comportamento, de olhar para si mesmo e se autocoagir. Aos poucos, os hábitos se internalizam e passa a haver o que conhecemos como autocontrole. A implementação do autocontrole faz com que pareça à mente do indivíduo que tal comportamento é resultado de seu livre-arbítrio, ou que faz parte de seu interesse pelas regras de higiene ou saúde, ou mesmo da dignidade humana.

Essas são, portanto, indicações de alterações na estrutura da sociedade que, conforme sabemos, nem sempre foi pacífica. Ao aprofundar o estudo sobre violência diante do processo de civilização, é importante compreender de que maneira as tensões existentes entre indivíduo e sociedade influenciaram, e ainda podem influenciar, o comportamento violento e qual a relação que se pode estabelecer entre eles.

\section{A infância e a família}

Os cuidados com a infância iniciaram-se no âmbito social que denominamos família. $\bigcirc$ conceito de família assume diversas características de acordo com configurações diferentes, conforme a época e o lugar em que se encontram. Portanto, é preciso ter em mente que as relações das crianças na sociedade, intermediadas pela família, são um fenômeno mutável no tempo, uma instituição social e historicamente situada, sujeita a mudanças de acordo com as diferentes relações estabelecidas entre os homens.

Cambi (1999) defende a ideia de que a família assumia diferentes configurações na Baixa ldade Média, desde o modelo de família patriarcal até o modelo nuclear, porém, diferentes do padrão de família moderna e burguesa, pois a medieval era aberta à sociedade sem se fechar em um núcleo privado. Sendo assim, não permanecia fechada dentro de casa, mas na rua, fazendo parte de todas as demais relações que ali se desenvolviam. Insuficientemente estruturada, a família medieval era, portanto, uma continuidade da vida social 
e tinha a preocupação com a criação de filhos. Porém, sua representação de um papel social não entendia a necessidade de envolver seus filhos com cuidados especialmente desenvolvidos para protegê-los.

Nesse sentido, Ariès (1981) mostra que os laços de sangue formavam dois grupos distintos: a família, que pode ser comparada à nossa família conjugal moderna, e a linhagem que era formada por todos os descendentes de um mesmo ancestral. $\bigcirc$ grupo familiar, portanto, era composto por diversos casais com seus filhos que moravam sob o mesmo teto para não ter que dividir as propriedades, o que ocasionava sua desvalorização e o enfraquecimento da linhagem.

A necessidade de proteção de grupos externos às famílias levou ao fortalecimento da linhagem. Os indivíduos passaram a buscar refúgio na linhagem porque sabiam que a qualquer momento poderiam sofrer ataques de grupos rivais que buscavam tomar suas terras.

A reunião dos indivíduos já unidos pela consanguinidade proporcionava a possibilidade de preservação também do grupo familiar mais restrito. (ARIÈS, 1981 ; ELIAS, 1993).

Por outro lado, é importante frisar que os costumes, e não os sentimentos, regiam os relacionamentos e comportamentos, por isso, atitudes, que para nós hoje parecem frias e despossuídas de amor, representavam o modo como as pessoas da época aprenderam a dirigir a educação e criação dos filhos. Exemplo disso era o afastamento da criança de sua casa para viver com outra família assim que completava sete ou oito anos de idade, servindo nos afazeres domésticos e aprendendo diferentes costumes e ofícios, bem como as "boas maneiras". Esses filhos retornariam apenas de sete a nove anos mais tarde, portanto, entre os quatorze e dezoito anos de idade (ARIĖS, 1981 ; HEYWOOD, 2004).

Eram altos os índices de mortalidade infantil na ldade Média e, de acordo com Ariès, pouca importância se dava à criança por tão longo período devido à facilidade em perdê-las. Por isso, as pessoas consideravam não ser aconselhável se apegar a elas. O grande número de doenças sem cura, a falta de saneamento básico, a má alimentação trazia muitas doenças e a sobrevivência das crianças nesse mundo era algo realmente muito raro. Por isso, havia uma insensibilidade natural com relação a uma infância demasiadamente 
frágil. O nível de mortalidade infantil era muito alto e o sentimento existente era de que se a família perdesse uma criança, outra viria em seu lugar.

Heywood (2004), porém, não acredita que a idéia de que os pais se mostrassem indiferentes à perda de um filho possa ser generalizada a todas as pessoas da época. De acordo com seus estudos, existem indícios tanto de que houvesse sentimento de profundo pesar por seus filhos quanto de indiferença por sua perda. Ocorre é que algumas proposições devem ser consideradas antes de se chegar a qualquer conclusão. Primeiro que todos os historiadores aceitam a ideia de que a perda de um filho de mais idade, com quem os pais já estabeleceram um vínculo mais forte, seria muito mais traumática do que a perda de um recém-nascido. Depois, que ao mesmo tempo em que podemos encontrar essa figura de pais em luto, representada por pessoas "chorando, gritando, implorando", havia o forte sentimento religioso de que os indivíduos deveriam ser submissos diante da vontade de Deus, agradecidos por tudo que acontecesse em suas vidas. Não deviam questionar os acontecimentos, fossem eles quais fossem. $\bigcirc$ autor se refere a uma

[...] tensão entre luto privado e estoicismo público entre cristãos devotos. Os moralistas durante a Idade Média aconselhavam comedimento: se o nascimento de um filho era um dom de Deus, também o era a sua morte, e simples mortais não deveriam questionar o julgamento divino (HEYWOOD, 2004, p. 80).

Um forte argumento utilizado para se defender a indiferença com relação à infância durante a ldade Média e início da ldade Moderna é a insensibilidade em relação à criação de filhos. Uma prática relacionada pelos críticos como descaso pelas crianças foi a de envio de bebês recém-nascidos às amas-de-leite. Porém, alguns autores nos mostram que até o final do século XIX, a ama-de-leite era a alternativa mais segura de alimentação da criança que não pudesse ser amamentada por sua mãe (HEYWOOD, 2004; GÉllS, 2001; MARCÍlIO, 1998).

Alguns fatores mostram a necessidade de amas-de-leite na época. Em primeiro lugar, o fato de que essa fosse a melhor e talvez única alternativa, especialmente nas regiões mais quentes onde o leite e outros produtos azedavam ou se contaminavam rapidamente. Heywood (2004), também apresenta o preconceito em relação ao leite animal, uma vez que as pessoas imaginavam que as crianças herdavam as características de quem as alimentava, o 
que levava as famílias a procurar por amas-de-leite que fossem gentis com as crianças, que tivessem boa saúde e fossem capazes de produzir leite sem contaminações. Outro motivo para se recorrer às amas-de-leite foi o fato de muitas mães apresentarem problemas de saúde. E, finalmente, a demonstração de nobreza, que se imaginava estar presente no fato de transferir as responsabilidades com o cuidado dos filhos para outras pessoas, o que levava as mães da classe mais alta a o fazerem sem hesitar.

Outro problema vivenciado pelos pais na criação de seus filhos estava relacionado à necessidade em mantê-los aquecidos. Heywood (2004) relata que as crianças eram amarradas firmemente com faixas de tecido sobre suas roupas durante parte do primeiro mês de suas vidas. Em toda a parte, os bebês eram enfaixados com os braços presos próximos à lateral do corpo e as pernas estendidas juntas com um suporte adicional para manter a cabeça firme. Em etapa posterior, braços e cabeça eram deixados livres até que a faixa pudesse ser retirada completamente. Todos esses cuidados se relacionavam em primeiro lugar à ignorância em relação ao desenvolvimento físico da criança. Imaginava-se que haveria problemas de coluna se isso não fosse feito, mas esse costume também ajudava a manter a criança aquecida.

16 Críticas a tal prática defendiam que a restrição aos movimentos impediria a respiração da criança, fora o fato de deixá-la enrolada em sua urina e fezes por longos períodos. Em alguns lugares, após serem amarradas, as crianças eram penduradas em um gancho enquanto a mãe poderia realizar outras atividades. Alguns críticos perceberam que tais práticas, sim, poderiam resultar em problemas na coluna das crianças, ocasionando o surgimento de "[...] corcundas, mancos, cambaios, raquíticos, pessoas deformadas de todo o tipo" (HEYWOOD, 2004, p. 96).

Outro problema que chama a atenção a respeito das relações entre infância e família na ldade Média é o infanticídio ou assassinato de filhos. Embora o problema tenha sido muito grave em diversas regiões da Europa, poucos foram os registros oficiais desse tipo. Uma das causas da ausência de relatos se deve ao fato de que o Direito ocidental demorou a reconhecer o ato de matar um bebê recém-nascido como crime e de considerá-lo tão grave quanto um homicídio cometido contra um adulto. Havia o entendimento de que o pai teria o direito de escolher o destino de seus filhos. Em alguns lugares, o pai que fosse pobre, ou tivesse um filho defeituoso, poderia escolher se queria que ele vivesse, ou não. As sociedades medievais tratavam o infanticídio 
mais como um pecado do que como um crime (HEYWOOD, 2004; MARCílIO, 1998).

Diversos autores mostram que o infanticídio não alcançou maiores proporções devido à facilidade que existia em se abandonar os bebês. Na alta Idade Média, as crianças já eram expostas nas ruas, vendidas pelos pais, doadas a uma casa religiosa ou aos ricos como servas. No século XVII, a criação da Roda dos Expostos em hospitais pertencentes a ordens religiosas ajudou na diminuição do infanticídio. Porém, nesses lugares, as crianças estavam praticamente condenadas à morte. Contando com orçamentos mínimos, tais instituições dependiam de amas-de-leite mercenárias para alimentar os bebês e muitas delas chegavam a alimentar até quatro crianças ao mesmo tempo (MARCÍlIO, 1998; PASSETI, 2000; HEYWOOD, 2004).

Gélis (2001) alerta para outra questão em relação à infância na ldade Média que é a de criança "pública". Para o autor, o sentimento em relação ao próprio corpo nesse momento era bem diferente do que possuímos atualmente. Cada indivíduo sentia seu corpo como pertencente a uma linhagem, à uma grande família. Seu corpo era seu, mas também um pouco dos outros. Assim, o indivíduo dispunha do próprio corpo somente na medida em que não contrariasse os interesses da família. Seu dever se resumia em dar vida. Nesse imaginário, a criança era considerada um "rebento do tronco comunitário" e, assim, era uma criança "pública". Após o desmame, a parte pública da educação da criança tendia a ser ampliada (GÉLIS, 2001).

Vários rituais deveriam ser realizados com a criança e esses eram quase atos públicos aos olhos de todos. $\bigcirc$ próprio batismo era considerado um rito de socialização da criança que, ao mesmo tempo, era a oportunidade de eliminar o pecado de seu coração. Após esse momento, uma série de rituais era realizada, envolvendo grande número de pessoas, sempre pensando em trazer benefícios ao pequeno. A partir daí, apesar da educação principal da criança ser responsabilidade dos pais, a coletividade participava de seu preparo para viver em sociedade.

De acordo com o autor, no final do século XIV, começou a surgir uma vontade cada vez maior de se preservar a vida da criança. Não que antes os pais não quisessem ver seus filhos vivos, "porém a consciência da vida, do ciclo vital era diferente, e não thes restava outro recurso senão ter mais um filho." Nesse momento, se começou a pensar em como preservar essa criança 
especificamente, um tempo em que também surgiram as preocupações com a própria saúde.

No passado, os vínculos de dependência em relação à parentela eram vividos carnalmente; agora, eles se distendem: 'meu corpo é meu', e procuro poupá-lo de doenças e sofrimento; mas sei que ele é perecível e, assim, continuo a perpetuá-lo através da semente de outro corpo, do corpo de meu filho (GÉllS, 2001, p. 317).

A criança passou a ocupar lugar importante nas preocupações dos pais. Eles amavam essa criança em sua individualidade e ela é sua alegria de cada dia. Essa mudança cultural, que a alteração de atitude em relação à criança demonstra, ocorreu ao longo de um período extenso e Gelis (2001) afirma que não se manifesta de forma linear. Em cada lugar acontece de maneira e em momentos diferentes. Para o autor, o interesse ou a indiferença em relação à criança não são características de um ou de outro período da história. "As duas atitudes coexistem no seio de uma mesma sociedade, uma prevalecendo sobre a outra por motivos culturais e sociais" (GÉLIS, 2001, p. 328).

18 fato é que a criança começa a ser valorizada individualmente, e não pode ser substituída por outra porque passa a ser considerada única e insubstituível. Cresce assim, o sentimento de carinho em relação a uma determinada criança, com suas individualidades e características que the são únicas. Ela não é mais vista como mais uma em meio a tantas outras que vêm e que podem ir, mas como alguém especial, insubstituível em sua singularidade.

\section{Considerações finais}

A dificuldade de perceber a infância e suas peculiaridades, como acontecia na ldade Média, não pode ser compreendida como uma total falta de preocupação ou de amor pela criança naquele momento. Muitos problemas cercavam as pessoas de um modo geral e, nesse contexto, a infância também sofria. A compreensão das concepções de "processos de civilização" e de "controle de pulsões e emoções", de Norbert Elias, e seus conceitos de "figuração", "interdependência", "psicogênese", "sociogênese", "poder" e "habitus" trouxeram a possibilidade de percepção da maneira como a mudança nas 
estruturas psíquicas e emocionais da sociedade puderam alterar as formas como os indivíduos passaram a ver e a tratar as crianças.

Dos conceitos do autor aqui analisados, foi possível compreender que, dentro de uma sociedade, todos podem exercer "poder" uns sobre os outros, desde que seu valor social seja reconhecido. Assim, o equilíbrio de "poder" é um elemento de grande importância nas relações sociais, pois quanto mais se encontrar equilibrado entre os integrantes da sociedade, mais controladas podem ser as relações. Por outro lado, as mudanças sociais de comportamento - dentre elas, a de percepção, compreensão e valorização da infância - só são possíveis à medida que ocorram alterações no "habitus" da sociedade, ou seja, que ocorram alterações psíquicas.

Por meio das concepções de "figuração" e "interdependência" foi possivel compreender que os indivíduos estabelecem suas relações e agem dentro da sociedade exercendo controle e sendo controlados. As pessoas que, na concepção de Elias, estão totalmente ligadas e entrelaçadas nessas relações sociais exercem seus papéis no sentido de fazer com que o "jogo" social se realize. O conceito de "psicogênese" possibilitou a compreensão das alterações que ocorrem na estrutura psicológica dos indivíduos num processo de longa duração a que são constantemente submetidos para o controle de suas pulsões. Já a "sociogênese" se refere às alterações ocorridas na sociedade devido às mudanças de comportamentos dos indivíduos.

Para Elias (1994), os processos de civilização não são compostos por uma série de relações causais, mas são provenientes de uma correspondência constante entre as modificações das estruturas da personalidade e as alterações das estruturas sociais, sem que se possa identificar um ponto inicial. Assim, a civilização é resultado, dentre outras coisas, de um processo de alteração no controle das emoções que se encontra relacionado ao crescente grau de entrelaçamento e interdependência entre as pessoas que compõem a sociedade.

Um maior controle das emoções trouxe também maior comedimento dos homens em relação aos indivíduos que poderiam ser considerados mais fracos, categoria na qual é possível, genericamente, encaixar crianças. Em contrapartida, o desenvolvimento de um modo de ver o outro, mais voltado para uma perspectiva psicológica, permite que se perceba esses indivíduos como pessoas, com suas peculiaridades. Assim, ocorre uma mudança no olhar 
sobre a infância, permitindo que a criança comece a fazer parte das relações de poder, pois esses indivíduos alcançaram importância social nesse processo de valorização e, de alguma forma, a sociedade passa a ser pressionada a atender às suas necessidades.

caminho percorrido pelo homem no controle de suas pulsões o leva a um maior comedimento de atitudes em relação àqueles que podem ser considerados mais vulneráveis perante a sociedade. Nesse sentido, a criança, ainda que não seja desprovida de certo poder, é vista como um dos indivíduos potencialmente mais fracos dentro das relações sociais.

\section{Referências}

ARIÈS, Philippe. História social da criança e da família. Rio de Janeiro: LTC, 1981. BRANDÃO, Carlos da Fonseca. Os processos de civilização e o controle das emoções Bauru: Edusc, 2007.

CAMBI, Franco. História da pedagogia. São Paulo: Editora da UNESP, 1999.

20 CHARTIER, Roger. Prefácio. ELIAS, Norbert. A sociedade de corte: investigação sobre a sociologia da realeza e da aristocracia de corte. Rio de Janeiro: Zahar, 2001.

ELIAS, Norbert. O processo civilizador: formação do Estado e civilização. Rio de Janeiro: Jorge Zahar, 1993. (v. 2).

ELIAS, Norbert. 0 processo civilizador: uma história dos costumes. 2. ed. Rio de Janeiro: Jorge Zahar, 1994. (v. 1).

ELIAS, Norbert. Os alemães - a luta pelo poder e a evolução do habitus nos séculos XIX e XX. Rio de Janeiro: Zahar, 1997.

ELIAS, Norbert. A sociedade de corte: investigação sobre a sociologia da realeza e da aristocracia de corte. Rio de Janeiro: Zahar, 2001.

ELIAS, Norbert. Introdução à sociologia. Tradução Maria Luiza Ribeiro Ferreira. Lisboa: Edições 70, 2008.

GÉllS, Jacques. A individualização da criança. In: ARIÈS, Philippe; CHARTIER, Roger. História da vida privada. Da Renascença ao Século da Luzes. São Paulo: Companhia das Letras, 2001 . (v. 3).

HEYWOOD, Colin. Uma história da infância. Porto Alegre: Artmed, 2004. 
MARCÍlIO, Maria Luiza. História social da criança abandonada. São Paulo: Hucitec, 1998.

NOGUEIRA, lone da Silva Cunha. O papel do Estado na proteção aos direitos de crianças e adolescentes no Brasil: as especificidades da Constituição Federal, do Estatuto da Criança e do Adolescente e da Lei de Diretrizes e Bases da Educação. 20 10. 164 f. Tese (Doutorado em Educação) - Programa de Pós-Graduação em Educação, Universidade Estadual Paulista "Júlio de Mesquita Filho", Campus de Marília, 2010.

PASSETI, Edson. Crianças carentes e políticas públicas. In: DEL PRIORE, Mary (org.). História das crianças no Brasil. São Paulo: Contexto, 2000.

ROTTERDAM, Erasmo. A civilidade pueril. São Paulo: Escala, s/d.

Prof. Dra. lone da Silva Cunha Nogueira Universidade Federal de Mato Grosso do Sul (Brasil)

Programa de Pós-Graduação em Educação

Grupo de Estudos e Pesquisas em Educação e Sociedade (UFMS) Coletivo de Pesquisadores em Políticas Educacionais (COPPE - UNESP) Orcid id: http:/ / orcid.org/0000-0003-4179-2 166

E-mail: ionescnogueira@gmail.com

Prof. Dr. Carlos da Fonseca Brandão Universidade Estadual Paulista "Júlio de Mesquita Filho" (Brasil) Departamento de Educação (UNESP) Programa de Pós-Graduação em Educação (UNESP/Marília) Coletivo de Pesquisadores em Políticas Educacionais (COPPE - UNESP) Orcid id: http: / / orcid.org/0000-0003-2254-0692 E-mail: carlos.brandao@unesp.br

Recebido 19 maio 2020

Aceito 2 jun. 2020 